\title{
Millennial-Scale Asian Monsoon Influenced Longjie Lake Evolution during Marine Isotope Stage 3, Upper Stream of Changjiang (Yangtze) River, China
}

\author{
Chaozhu Li, ${ }^{1}$ Jianli Fu, ${ }^{1}$ Liang Yi, ${ }^{2}$ Xin Zhou, ${ }^{3}$ Shubing Wang, ${ }^{1}$ and Fuchu Jiang ${ }^{1}$ \\ ${ }^{1}$ Institute of Geomechanics, Chinese Academy of Geological Sciences, Beijing 10081, China \\ ${ }^{2}$ MSG Group, Sanya Institute of Deep-Sea Science and Engineering, Chinese Academy of Sciences, Sanya 572000, China \\ ${ }^{3}$ School of Earth and Space Sciences, University of Science and Technology of China, Hefei 230026, China \\ Correspondence should be addressed to Chaozhu Li; lichzh@163.com
}

Received 6 February 2015; Revised 20 April 2015; Accepted 20 April 2015

Academic Editor: Steffen Mischke

Copyright (C) 2015 Chaozhu Li et al. This is an open access article distributed under the Creative Commons Attribution License, which permits unrestricted use, distribution, and reproduction in any medium, provided the original work is properly cited.

\begin{abstract}
Millennial-scale climate change in Asian monsoon region during MIS 3 has been studied using stalagmite, loess, and peat sediments. However, records from more materials are essential to further illustrate dynamics of these events. In the present study, a time-series of grain size covering 60-30 ka was reconstructed from lake sediments in the Yunnan Province, southwestern China. The time-series contains 14 obvious millennial-scale events during the period. On millennial-scale, the grain size record is generally consistent with mean stalagmite $\delta^{18} \mathrm{O}$ from Hulu Cave, grain size of Gulang loess sequence, Chinese Loess Plateau, and Greenland ice core $\delta^{18} \mathrm{O}$. The results show that the millennial-scale variation was well compared with the Dansgaard-Oeschger (DO) events, indicating that those global events were well documented in lake sediments in the Asian monsoon region. Because the grain size can be used as a proxy for water discharge, we suggest that signal of the DO events might be transmitted to lake evolution by Asian monsoon.
\end{abstract}

\section{Introduction}

Marine Isotope Stage 3 (MIS 3), with relatively warm and wet climate and high sea level, is a particular period during the last glacial $[1,2]$. The more attractive character during this period is the typical millennial-scale climate oscillations, which was named as Dansgaard-Oeschger (DO) events [3, 4], and has been extensively studied $[5,6]$. To date, studies on MIS 3 in China were mainly focused on how warm or/and wet the period was, especially on whether megalakes existed in northwestern China during this period [7-9].

Due to the lack of suitable materials, few records have been reconstructed to study millennial-scale climate events during the MIS 3 in China. Earlier studies [10,11] have characterized these events using magnetic susceptibility, grain size of quartz, and weathering indices in Chinese Loess Plateau. Recently, Sun et al. reconstructed two high-resolution and precisely dated winter monsoon records by loess sequences with high sedimentary rates, and attributed these abrupt events to variations in Atlantic meridional overturning circulation [12]. Because stalagmite can be precisely dated, more researches [13-15] used stalagmite to study millennial climate events during the MIS 3, since Yuan et al. published highresolution stalagmite $\delta^{18} \mathrm{O}$ records and compared them with Greenland ice core $\delta^{18} \mathrm{O}$ [13]. More recently, peat sediment has also been used to investigate millennial-scale climate changes [16]. However, lack of enough records limited the comparison of the events between different regions and studies on the forcing of the events during the MIS 3.

Yunnan Province is located in northwestern China and is thus sensitive to Asian monsoon changes. In the present study, we reconstructed climate change at a study site in Yunnan Province during the MIS 3, focusing on millennial-scale events and the transmitting mechanisms of the DO signal to lake evolution.

\section{Study Area, Materials, and Methods}

2.1. Longjie Silt Layers. Longjie Silt Layers [17] were located in the lower stream of the Jinshajiang River, which belongs to the upper stream of the Changjiang (Yangtze) River, where the 


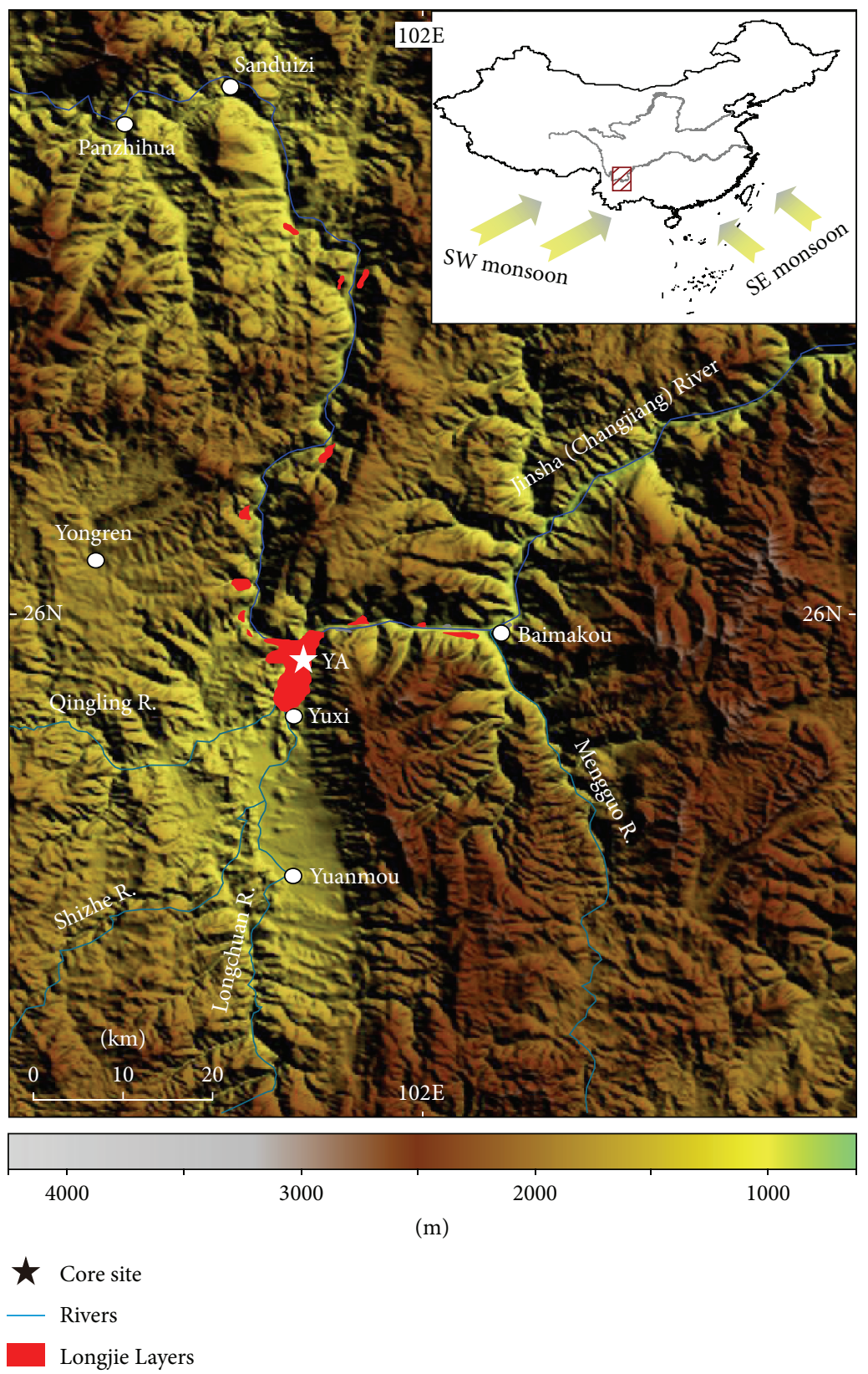

FIgURE 1: Study area, distribution of Longjie Silt Layers, and YA core site. The base map was generated using the open and free software DIVA-GIS 7.5 (http://www.diva-gis.org/).

climate is significantly influenced by the Asian monsoon with an annual precipitation of $800-1600 \mathrm{~mm}$. The Longjie Silt Layers are composed of grey white-grey, yellow-grey silt, clay silt, and clay, distributing along the Jinshajiang River between the Sanduizi and the Baimakou (Figure 1). Its thickness is commonly $40-50 \mathrm{~m}$, and the depositional environment is supposed to be shallow lake [18]. However, the formation, mechanism, and controlling factors of this lacustrine layer are still unclear [19-22].

2.2. YA Core. The YA core was located on the southern side of the modern Jinshajiang River, $57 \mathrm{~m}$ higher relative to present river level $\left(101^{\circ} 52^{\prime} 56^{\prime \prime} \mathrm{E}, 25^{\circ} 57^{\prime} 34^{\prime \prime} \mathrm{N}\right.$; elevation $979 \mathrm{~m}$, Figure 1). The length of core obtained from the drill site was $91.9 \mathrm{~m}$ and the recovery rate was $>95 \%$. An exceptional section of the record, raised from 11.0 to $30.0 \mathrm{~m}$ below the core top, was selected here for study, because of being well constrained by luminescence dating. This sediment interval is composed of yellow-grey fine to coarse silt, namely, the Longjie Silt Layers, which is similar in composition to the modern sediment in the Jinshajiang River (upper stream of Changjiang River). This unit is interpreted as a lacustrine environment, and the vertical variation of these sedimentary facies is depicted in Figure 2. 


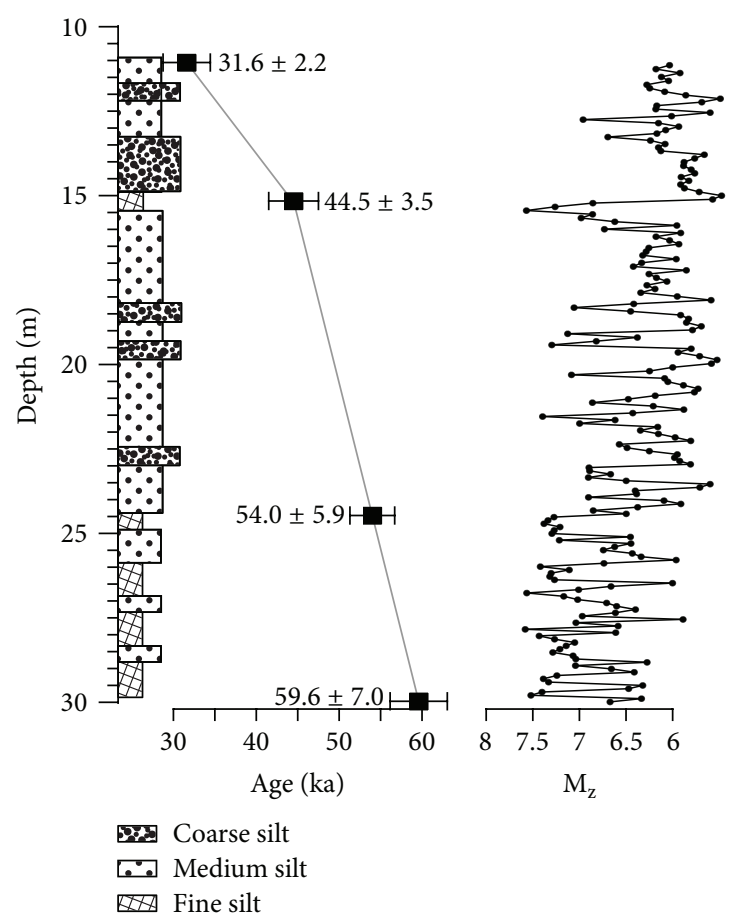

(a) (b)
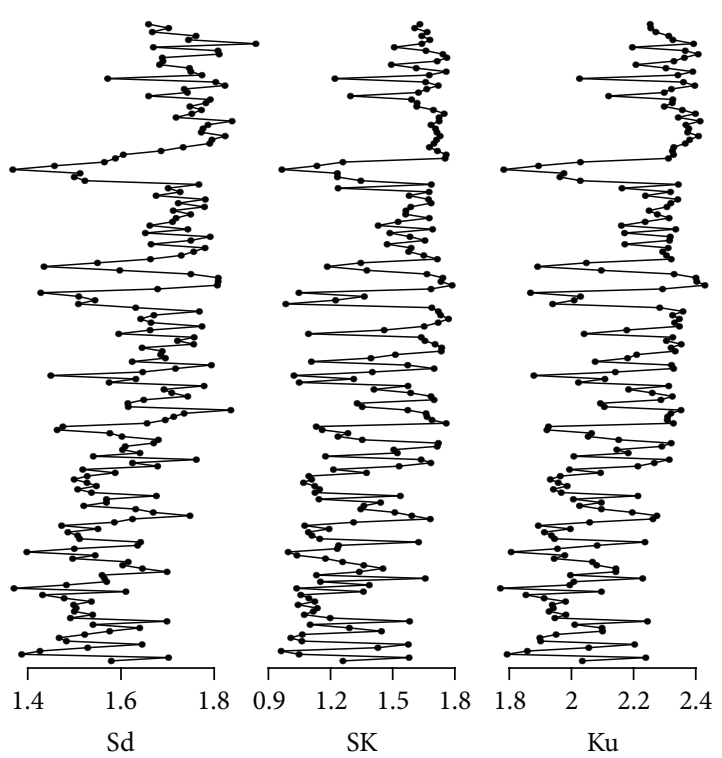

(d) (f)

FIgUre 2: Profile (a), OSL ages (b), and grain size variation (c-f) of YA core.

2.3. Luminescence Dating. Four samples (Figure 2) were collected for optically stimulated luminescence (OSL) dating by hammering metal cylinders of $2.5 \mathrm{~cm}$ (diameter) $\times 6 \mathrm{~cm}$ (length) horizontally into cores. Sample preparation was conducted under subdued red light. The light-exposed sediment was removed from both ends of the cylinders. All samples were pretreated with $10 \% \mathrm{HCl}$ and $30 \% \mathrm{H}_{2} \mathrm{O}_{2}$ to remove carbonates and organics, respectively. To remove feldspars, the quartz fraction of fine silty grains $(4-11 \mu \mathrm{m})$ was then treated with silica saturated fluorosilicic acid $\left(\mathrm{H}_{2} \mathrm{SiF}_{6}\right)$ for about two weeks $[23,24]$. The purity of the prepared quartz was tested by routine IR stimulation. Any sample with detectable decaying IRSL signal above the background was reetched with $\mathrm{H}_{2} \mathrm{SiF}_{6}$ to avoid the age underestimation that may originate from the contamination of feldspars [25]. For equivalent dose determination, we followed the sensitivity-corrected multiple aliquot regenerative-dose protocol given by Lu et al. [26], performing on a Daybreak 2200 automated OSL reader in the OSL laboratory, Institute of Hydrogeology and Environmental Geology, Chinese Academy of Geological Sciences.

The concentrations of uranium (U), thorium (Th), and potassium $(\mathrm{K})$, involved in dose rate calculations, were measured by neutron activation analysis in the China Institute of Atomic Energy in Beijing. The cosmic-ray dose rate was estimated according to Prescott and Hutton [27]. The dose rate of each sample was then calculated following the method of Aitken [28].

2.4. Sediment Grain Size. A total of 183 grain size samples were measured at a $10 \mathrm{~cm}$ sampling interval. The grain size samples were pretreated with $10-20 \mathrm{~mL}$ of $30 \% \mathrm{H}_{2} \mathrm{O}_{2}$ to remove organic matter, washed with $10 \% \mathrm{HCl}$ to remove carbonates, rinsed with deionized water, and then placed in an ultrasonic bath for several minutes to facilitate dispersion. The grain size spectra of the remaining terrigenous material were measured using a Malvern Mastersizer 2000 laserparticle size analyzer at East China Normal University. One hundred grain size classes between 0.2 and $200 \mu \mathrm{m}$ were exported for further analysis.

Sediment grain size is a powerful proxy for paleoenvironmental reconstruction because depositional interpretation varies with sedimentary grain size and composition. Because grain size spectra represent mixtures of sediment delivered by multiple processes, to identify the processes controlling grain size variation, varimax-rotated, principle component analysis (VPCA) is often employed. This method partitions the variance in the grain size data set into sediment input components that can be interpreted in terms of processes $[29,30]$.

\section{Results}

3.1. Chronology of YA Core. Parts $(\mathrm{a}-\mathrm{d})$ of Figure 3 show OSL decay curves of the natural dose $(\mathrm{N})$ and a regeneration dose. Their OSL signals decrease very quickly during the first ten seconds of stimulation, indicating that the OSL signal is dominated by the fast component. Parts $(\mathrm{e}-\mathrm{h})$ of Figure 3 show the growth curves. For all samples, the growth curves can be well fitted using the exponential form.

The water contents decrease stratigraphically with depth probably due to the lower part of the core being closer to the level of groundwater because of regional uplift. In contrary, the OSL ages from the YA core increase stratigraphically 


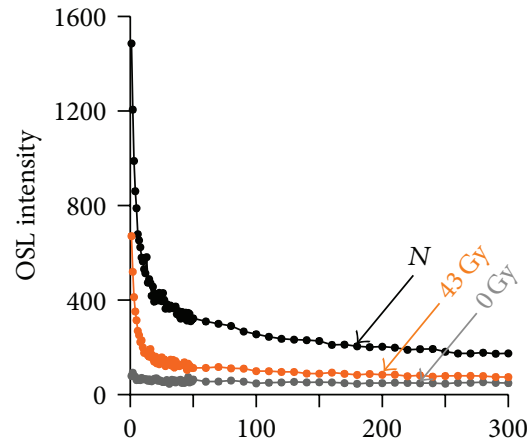

(a)

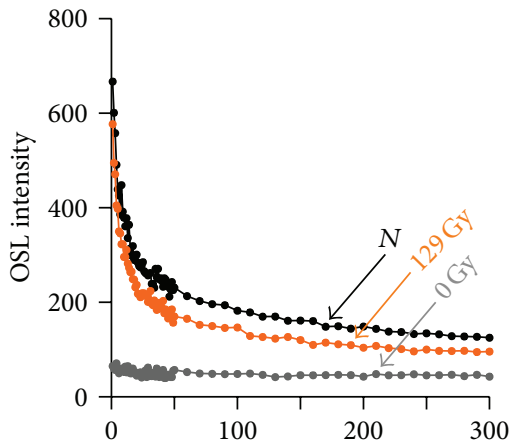

(b)

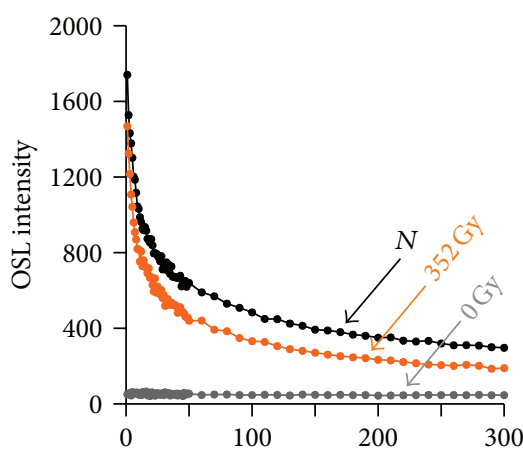

(c)

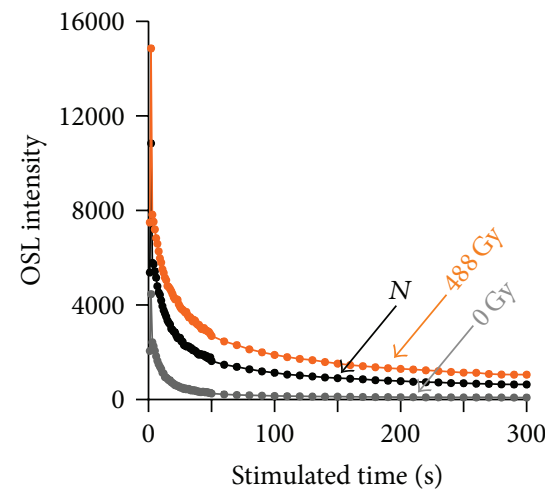

(d)

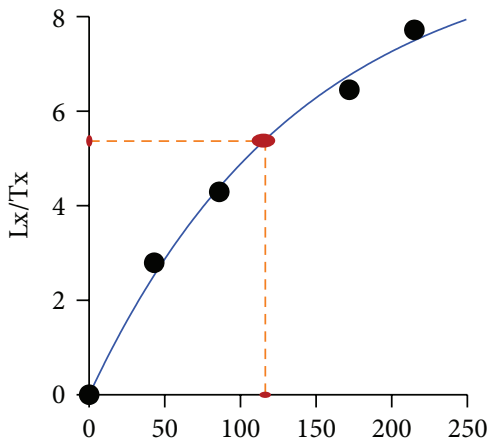

(e)

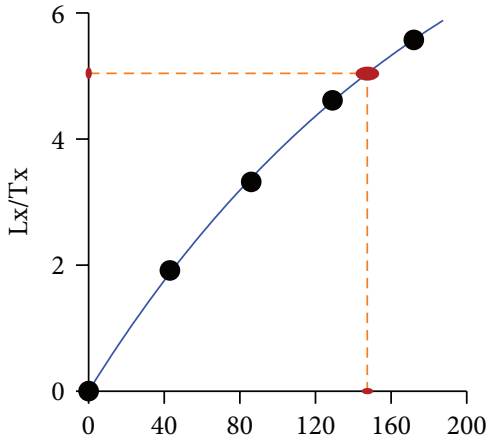

(f)

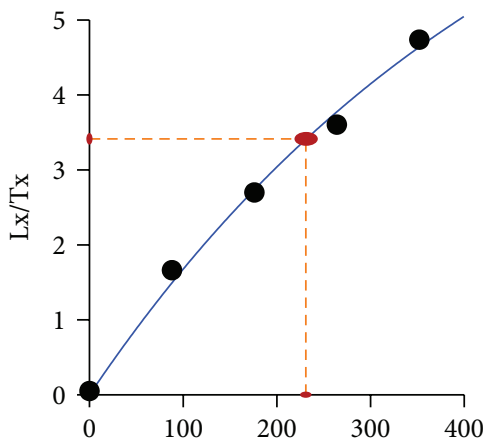

(g)

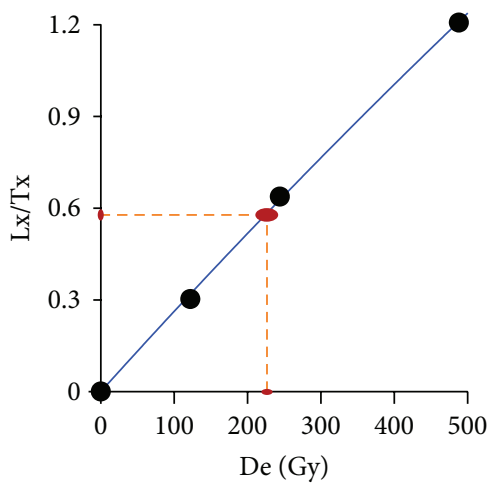

(h)

FIGURE 3: Luminescence decay (left panel) and growth (right panel) curves of Y-1 (a, e), Y-2 (b, f), Y-6 (c, g), and Y-8 (d, h), respectively. 
TABLE 1: Optically stimulated luminescence dating results of the YA core.

\begin{tabular}{|c|c|c|c|c|c|c|c|c|}
\hline Longjie YA core & Depth (m) & $\mathrm{U}(\mathrm{ppm})$ & Th (ppm) & $\mathrm{K}(\%)$ & De (Gy) & $\operatorname{Dr}(\mathrm{Gy} / \mathrm{ka})$ & Water (\%) & Age (ka) \\
\hline Y-1 & 11.1 & $2.66 \pm 0.015$ & $12.60 \pm 0.2$ & $1.58 \pm 0.05$ & $116.21 \pm 5.55$ & $3.68 \pm 0.38$ & $12.45 \pm 5$ & $31.6 \pm 2.2$ \\
\hline Y-2 & 15.2 & $2.70 \pm 0.015$ & $11.50 \pm 0.2$ & $1.48 \pm 0.05$ & $147.86 \pm 3.30$ & $3.32 \pm 0.20$ & $20.91 \pm 5$ & $44.5 \pm 3.5$ \\
\hline Y-6 & 24.5 & $3.06 \pm 0.015$ & $15.60 \pm 0.2$ & $2.23 \pm 0.05$ & $227.31 \pm 1.21$ & $4.21 \pm 0.17$ & $30.15 \pm 5$ & $54.0 \pm 5.9$ \\
\hline Y-8 & 30.0 & $2.36 \pm 0.015$ & $13.40 \pm 0.2$ & $2.05 \pm 0.05$ & $220.57 \pm 5.90$ & $3.70 \pm 0.15$ & $27.14 \pm 5$ & $59.6 \pm 7.0$ \\
\hline
\end{tabular}

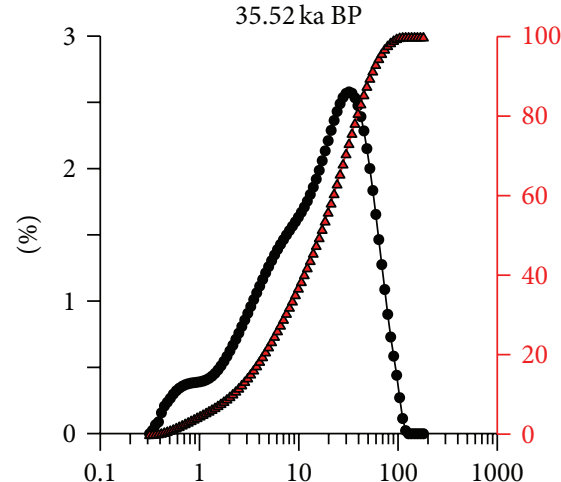

(a)

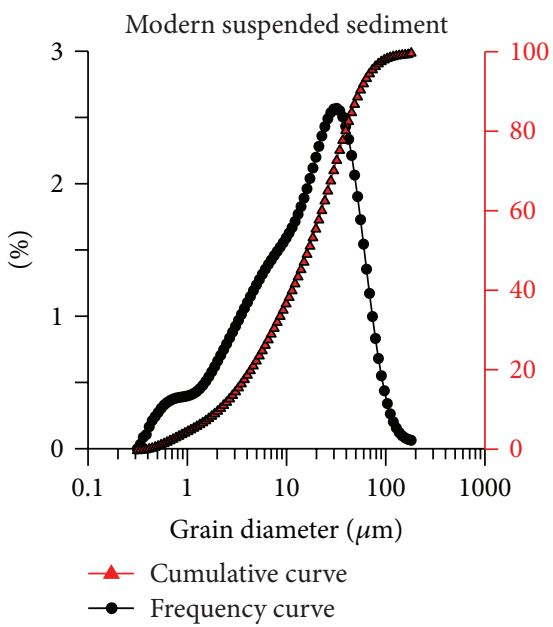

(d)

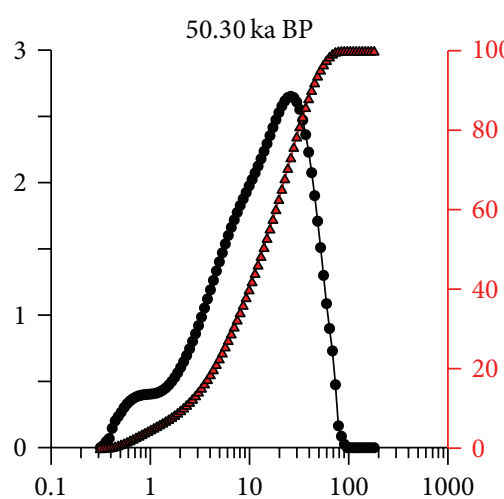

(b)

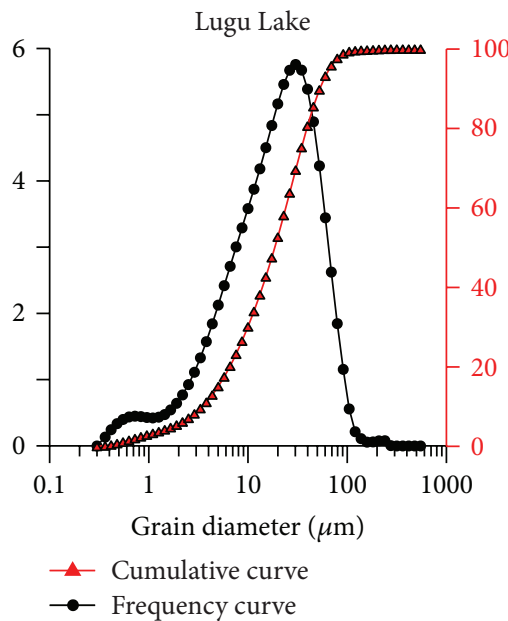

(e)

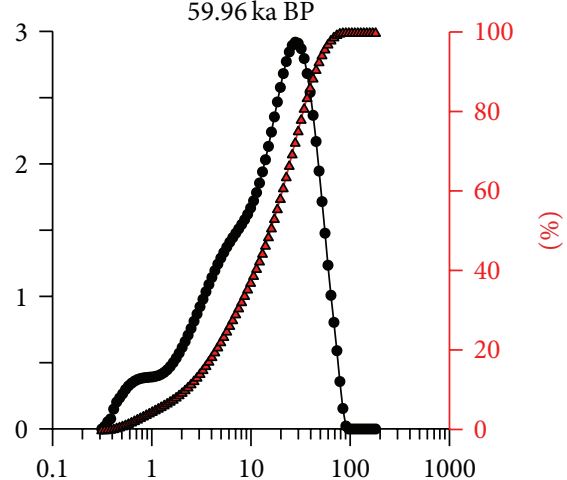

(c)

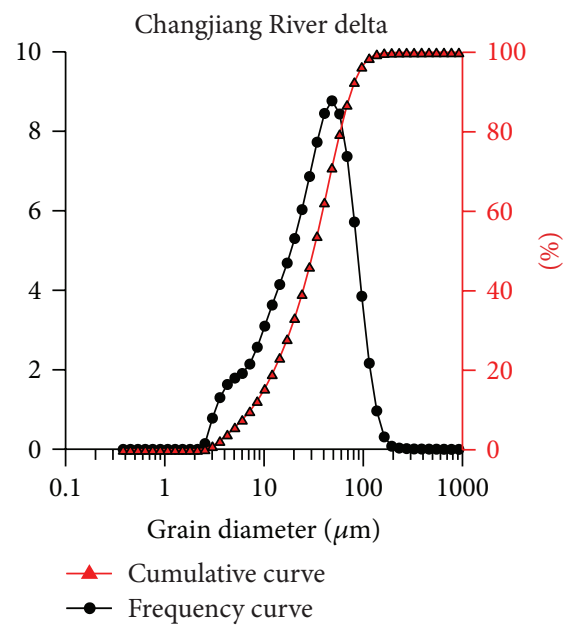

(f)

Figure 4: Grain size distribution of three samples from the Longjie Section (a-c) and three samples of modern suspended sediment (d), Lugu Lake ((e) Wang et al., 2014), and Changjiang River delta (f).

with depth (Table 1), indicating that, within the chronological resolution of the depth-age pairs, the sediment accumulation rate follows a clear relationship. To establish a depth-age transfer model, we apply a simply linear interpolation strategy to provide geochronological information for each grain size sample.

3.2. Grain Size Variation. Frequency and cumulative curves of grain size of three typical samples in Longjie Section show a similar distribution pattern (Figure 4), indicating that they were deposited under similar sedimentary environment. Furthermore, we found that these frequency and cumulative curves are similar to those of modern suspended sediment of the Jinshajiang River (this study) and Lugu Lake near the study area [31] but different from the modern sediment of Changjiang River delta [32] and loess deposits.

Variation in the clay, sand, and silt fractions is subtle in the younger sedimentary unit but more pronounced in the older stratigraphic unit (Figure 5). The grain size VPCA results of the individual data sets (Figure 6) indicate that the leading components, grain size component GSC-1 and GSC2 , account for roughly $78 \%$ of the variance in the down core sediment samples, while the minor components (GSC-3 and GSC-4) only account for less than $10 \%$ of the total variance.

To evaluate the environmental information included in these stable components for further analyses, we calculate the weighted average of the two leading components to form 


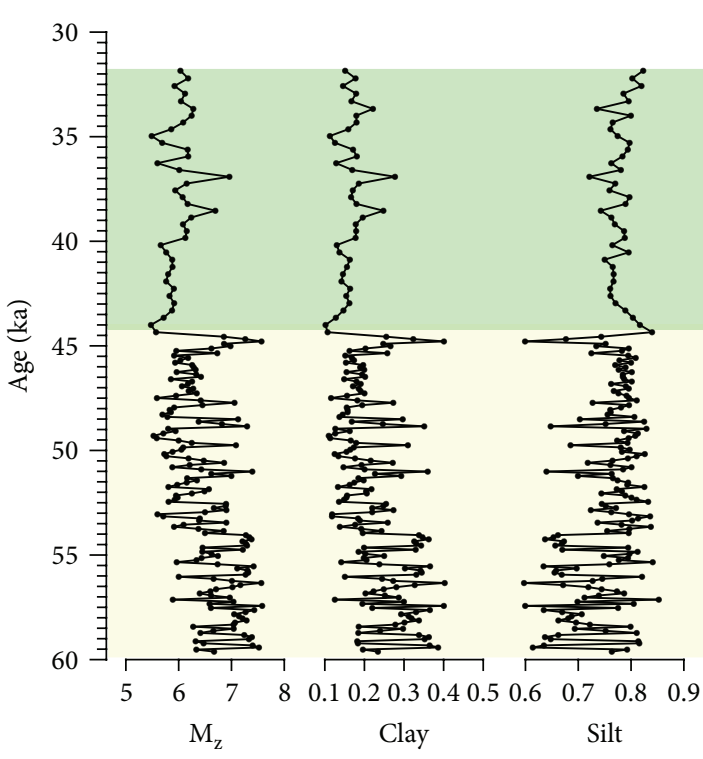

(a)

(b)

(c)

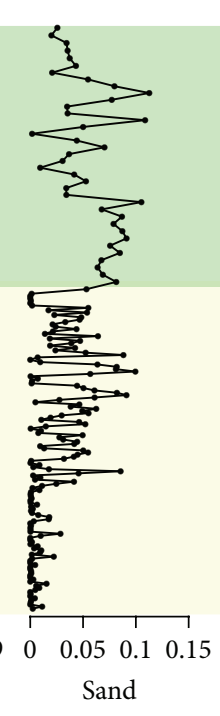

(d)

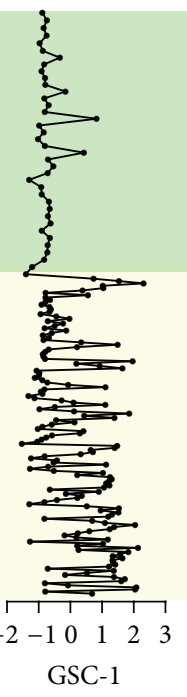

(e)

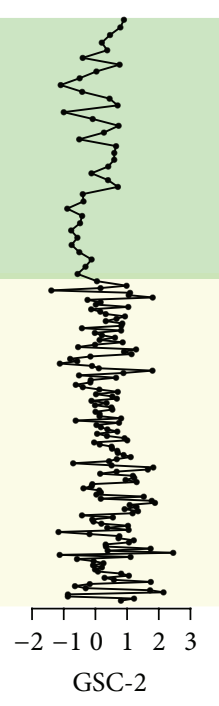

(f)

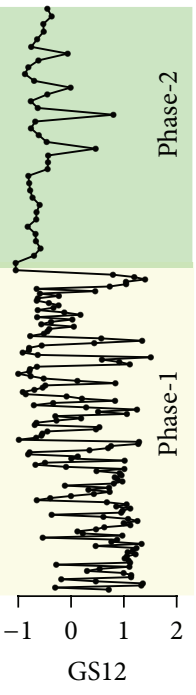

(g)

FIGURE 5: Sediment grain size (a-d) and its variation (e-g) derived from varimax-rotated, principle component analysis (VPCA).

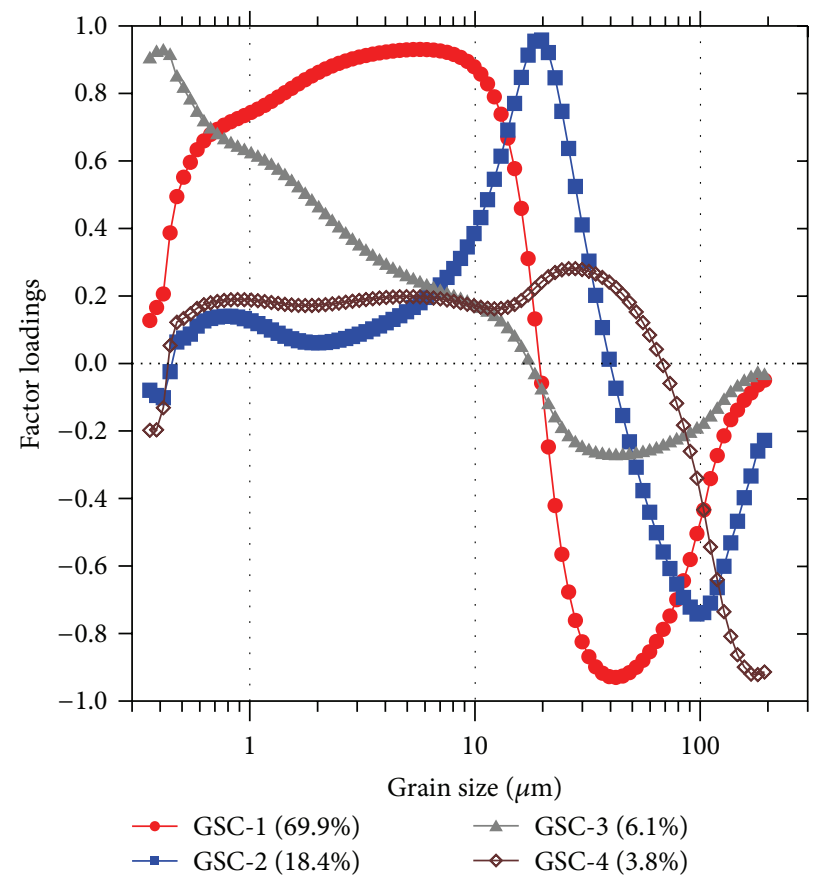

FIGURE 6: VPCA results from YA sediment and the percentage of each component.

a new series, GS12, which captures $78.3 \%$ of the overall grain size variability:

$$
\text { GS12 }=(69.9 \times \text { GSC-1 }+18.4 \times \text { GSC- } 2) \div 78.3 .
$$

The weighting coefficients are simply the percentage of variance associated with each component. This approach filters out the minor constituents from the grain size spectra using the data adaptive filters defined by the first and second components $[30,33]$.

\section{Discussion}

4.1. Interpretation of Sediment Grain Size. The sediment of the Longjie Silt Layers was supposed to be formed in fluvial or lake environments [20,34], and this hypothesis was verified [22] by field investigation and grain size comparison between Longjie sediment and Daihai [35] and Lugu Lake sediments [31]. Frequency and accumulative curves of grain size of most samples in the YA core share a common pattern, demonstrating a similar sedimentary environment through the MIS 3. 


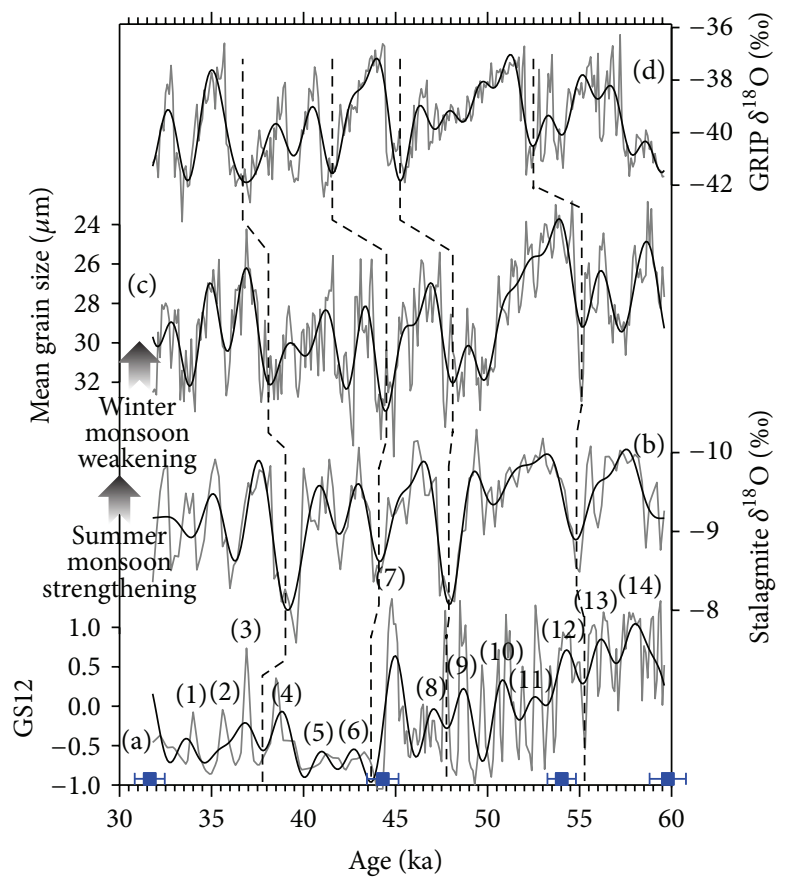

FIGURE 7: Comparison of grain size in Longjie Section (a) with stalagmite $\delta^{18} \mathrm{O}$ in Hulu Cave [36-39] (b), mean grain size of the Gulang loess sequence, Chinese Loess Plateau [12] (c), and Greenland ice core $\delta^{18} \mathrm{O}$ [40] (d). Thin lines represent original data, and bold lines were filtered from $1.5 \mathrm{ka}$ low-frequency pass process. Numbers labeled in (a) represent possible warm-wet events regarding Dansgaard-Oeschger (DO) events.

Furthermore, we found that the VPCA factor loadings of YA core are similar to those of shallow water sediments but different from those of the loess and river sand (see Figure 4 in [30]). Therefore, it is inferred that the sediment of YA core from the Longjie Silt Layers was deposited in a shallow-lake environment (Longjie Lake).

Because the Longjie Silt Layers distribute at the crosspoint of the Jinshajiang River and Longchuan River, there were two possible sources of the sediment in the Longjie Lake: (1) suspended from the Jinshajiang River and (2) trapped from the Longchuan River. As a branch, the runoff of the Longchuan River is only 1/60 of the runoff of the Jinshajiang River, and its sediment loads are also much smaller. In this context, it is supposed that fine grains might be mainly from suspended materials of the Jinshajiang River, somewhat similar as a flood plain of the Jinshajiang River, but the coarse grains were possibly from the Longchuan River due to gravitational differentiation. Thus, integrating positively from fine particles and negatively from coarse particles (Figure 6), the GS12 series can be an indicator of runoff variation of the Jinshajiang and Longchuan Rivers.

4.2. Lake Evolution within MIS 3 and Its Driving Forces. In general, GS12 variation can be grouped into two phases: great variability before $44 \mathrm{ka}$ and low variability after (Figure 5). From 60 to $44 \mathrm{ka}, \mathrm{GS} 12$ is characterized by high variation with distinct changes. During the early MIS 3, GS12 has an average value of 0.23 with a much larger value of standard deviation, 0.73 . This zone of high variability can be partitioned into dozens of substages and all of the transitions between each substage are abrupt. In contrast, from 44 to $30 \mathrm{ka}, \mathrm{GS} 12$ exhibits lower variation, with an average value of -0.40 and a moderate standard deviation of 0.60 . Subsequently, we divided lake evolution within the MIS 3 period into two stages: the first one was from 60 to $44 \mathrm{ka}$; frequent fluctuation of the GS12 series indicates a subperiod with high-frequency variation of water discharge and lake-level changes and the other was from 44 to $30 \mathrm{ka}$, and it is supposed to be a subperiod with relatively stable water discharge and lake level.

Because the YA core site is located within valleys of Jinshajiang catchments, rainfall and ice melting should be two major factors affecting river runoff. When precipitation increased, GS12 value will increase, while melting of ice and snow can be positively related to GS12 series. Thus, it is inferred that GS12 variation was mainly controlled by both monsoon precipitation and temperature on Tibetan Plateau.

Stalagmite $\delta^{18} \mathrm{O}$ has always been used to indicate Asian monsoon intensity [13, 36-39], although its indicative significance is still in debate [41-45]. Herein, we compared the GS12 with that of the stalagmite $\delta^{18} \mathrm{O}$ in Asian monsoon region. The results show that trends of the two time-series are roughly consistent on millennial-scale (Figure 7(b)). The consistence further confirms that stalagmite $\delta^{18} \mathrm{O}$ can be used as proxy of monsoon precipitation during MIS 3, and that summer monsoon signals recorded in different materials are comparable during the period.

To study the forcing mechanism and transmitting process of the millennial events during MIS 3, we then compared our GS12 with grain size variation of the Gulang loess sequence, Chinese Loess Plateau, considering the uncertainty 


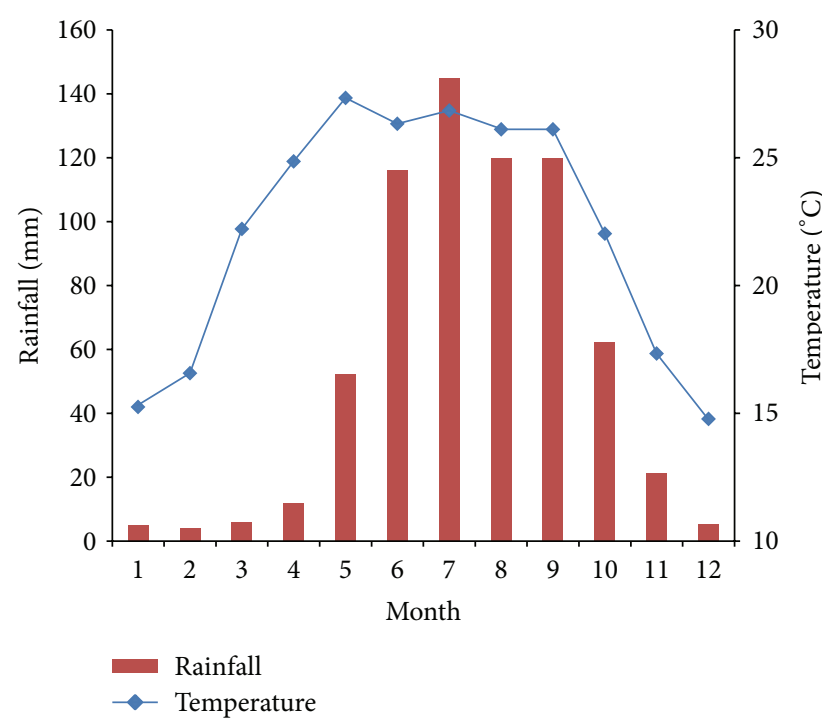

(a) Yuanmou

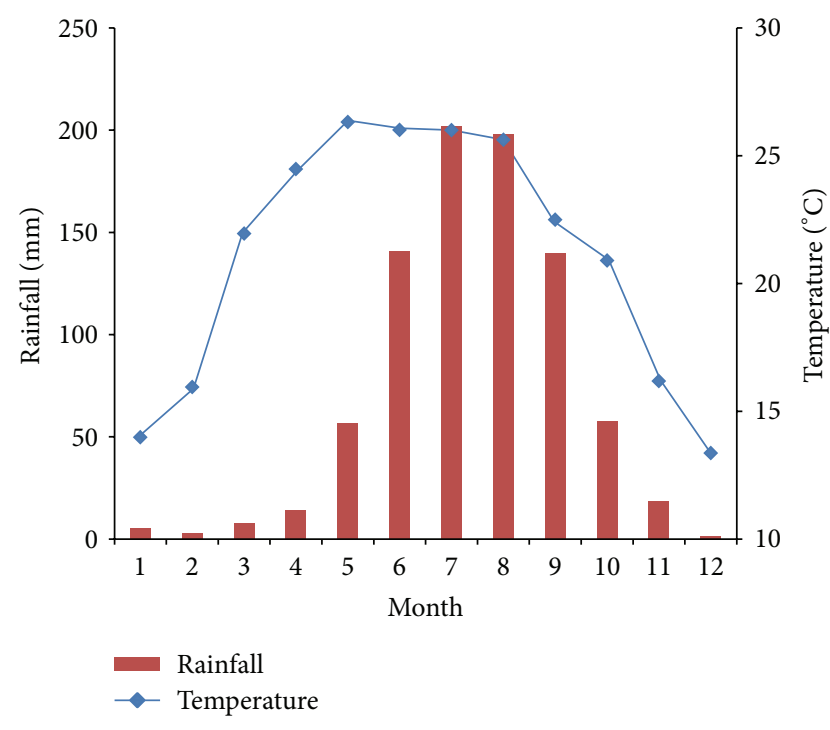

(b) Panzhihua

Figure 8: Monthly distributions of the precipitation and temperature of the Yuanmou (a) and Panzhihua (b) meteorological stations for 1951-2004 AD period.

of OSL dating (Figure $7(\mathrm{c})$ ). These variations are comparable between two records on millennial-scale, indicating the common forcing of Asian monsoon, as indicated by Sun et al. [12]. Additionally, we also found consistence with Greenland ice core $\delta^{18} \mathrm{O}$ series (Figure $7(\mathrm{~d})$ ).

Because the summer and winter monsoon are mainly considered as low- and high-latitude factors, respectively, the common forcing of the two signals should be linked to both low- and high-latitude processes. Generally, changes in summer and winter monsoon strength were attributed to shift of Intertropical Convergence Zone (ITCZ) and strength of the Siberia High, respectively. The northern westerly, located in the mid- to high-latitude, can influence both the ITCZ and the Siberia High. As indicated by earlier studies [12], slowdown of the Atlantic meridional overturning circulation would cause decreasing of temperature in the northern hemisphere and strengthen the northern westerly circulation. Then the winter monsoon would be strengthened during the cold periods, and the ITCZ would shift southward, causing the weakening of the Asian summer monsoon.

We therefore summarized the linkage between lake evolution recorded in the Longjie Silt Layers and commonly climatic forces as follows: when the winter monsoon strengthened and the summer monsoon weakened, winter snowfall increased but summer rainfall significantly decreased. Although melting snow would increase, because the summer rainfall accounts for $>80 \%$ of annual quantity (Figure 8 ), regional water discharge significantly decreased. Due to weakened hydrodynamics, lake sediment would become finer. However, possibly due to incised river channels and/or tectonic uplift, this paleolake turned far away or higher than the river base level, causing influences from climatic change and grain size variability significantly decreased from $60-$ $44 \mathrm{ka}$ to $44-30 \mathrm{ka}$. More evidence and further studies will be necessary to test the interaction between tectonic activity and climate change in the future.

\section{Conclusions}

In summary, a time-series for Longjie Silt Layers during the MIS 3 was reconstructed by grain size of lake sediments. The record contains a series of millennial-scale events, which are comparable with DO events in other Asian monsoon records. The consistence of these events in both summer and winter monsoon records indicated common forcing of summer and winter monsoon strength on millennial-scale during the period. The signal was suggested to be transmitted into lake evolution through physical relationship between climatic changes and regional water discharges and sediment transport.

\section{Conflict of Interests}

The authors declare that there is no conflict of interests regarding the publication of this paper.

\section{Acknowledgments}

The research was financially supported by National Natural Science Foundation of China (Project no. 40772211). And thanks for the help are due to Professor Hua Zhao, Institute of Hydrogeology and Environmental Geology, Chinese Academy of Geological Sciences.

\section{References}

[1] A. H. L. Voelker and Workshop participants, "Global distribution of centennial-scale records for Marine Isotope Stage (MIS) 
3: a database," Quaternary Science Reviews, vol. 21, no. 10, pp. 1185-1212, 2002.

[2] M. Siddall, E. J. Rohling, W. G. Thompson, and C. Waellbroeck, "Marine isotope stage 3 sea level fluctuations: data synthesis and new outlook," Reviews of Geophysics, vol. 46, no. 4, Article ID RG4003, 2008.

[3] W. Dansgaard, S. Johnsen, H. B. Clausen et al., "North Atlantic climatic oscillations revealed by deep Greenland ice cores," in Climate Processes and Climate Sensitivity, J. E. Hansen and T. Takahashi, Eds., pp. 288-298, American Geophysical Union, Washington, DC, USA, 1984.

[4] K. K. Andersen, N. Azuma, J.-M. Barnola et al., "High-resolution record of Northern Hemisphere climate extending into the last interglacial period," Nature, vol. 431, no. 7005, pp. 147151, 2004.

[5] L. A. Hinnov, M. Schulz, and P. Yiou, "Interhemispheric spacetime attributes of the Dansgaard-Oeschger," Quaternary Science Reviews, vol. 21, pp. 1213-1228, 2002.

[6] S. V. Petersen, D. P. Schrag, and P. U. Clark, "A new mechanism for Dansgaard-Oeschger cycles," Paleoceanography, vol. 28, no. 1, pp. 24-30, 2013.

[7] B.-Y. Li, "The last greatest lakes on the Xizang (Tibetan) plateau," Acta Geographica Sinica, vol. 55, no. 2, pp. 174-182, 2000.

[8] Y. Shi, Y. Jia, G. Yu et al., "Features, impacts and causes of the high temperature and large precipitation event in the Tibetan Plateau and its adjacent area during 40-30 ka BP," Journal of Lake Sciences, vol. 14, pp. 1-11, 2002.

[9] J. Wang, "Glacial advance in the Qinghai-Tibet Plateau and peripheral mountains during the mid-MIS 3," Quaternary Sciences, vol. 30, no. 5, pp. 1055-1065, 2010.

[10] S. C. Porter and A. Zhisheng, "Correlation between climate events in the North Atlantic and China during the last glaciation," Nature, vol. 375, no. 6529, pp. 305-308, 1995.

[11] Z. Guo, S. Peng, L. Wei, and T. Liu, "Weathering signals of millenial-scale oscillations of the East-Asian summer monsoon over the last 220 ka," Chinese Science Bulletion, vol. 44, pp. $20-$ 25, 1999.

[12] Y. Sun, S. C. Clemens, C. Morrill, X. Lin, X. Wang, and Z. An, "Influence of Atlantic meridional overturning circulation on the East Asian winter monsoon," Nature Geoscience, vol. 5, no. 1, pp. 46-49, 2012.

[13] D. Yuan, H. Cheng, R. L. Edwards et al., "Timing, duration, and transitions of the last Interglacial Asian monsoon," Science, vol. 304, no. 5670, pp. 575-578, 2004.

[14] K. Zhao, X. Kong, H. Cheng, and Y. Wang, "Intensity and timing of D-O events of East Asian monsoon during the late episode of MIS 3," Quaternary Sciences, vol. 28, no. 1, pp. 177-183, 2008.

[15] D. Liu, Y. Wang, S. Chen, H. Cheng, and R. L. Edwards, "SubDansgaard-Oeschger events of East Asian monsoon and their global significance," Quaternary Sciences, vol. 28, pp. 169-176, 2008.

[16] Y. Zhu, Z. Zhao, Y. Chen, M. Zhang, and G. Lei, "Record of envrionmental and millennial-scale climatic changes during MIS 3 by peat at Shennongjia," Quaternary Sciences, vol. 33, pp. 155-166, 2013.

[17] M. Bian, "Yuanmou Basin geology, Yunnan Province, China," Geological Society of China, vol. 20, pp. 23-33, 1940.

[18] C. Li, F. Jiang, J. Fu, and S. Wang, "The formation time of the Longjie silt layer in the Yuanmou Area, Yunnan Province," Quaternary Sciences, vol. 31, no. 5, pp. 933-934, 2011.
[19] W. Huang, J. Wang, Z. Que, and S. Zheng, "Geochronological comparison between Yuanmou, Longjie and Zigeda formations," Proceedings of Stratigraphy and Paleontology, vol. 7, pp. 30-39, 1978.

[20] L. Min, Z. Yin, and J. Zhang, "The formation time and paleoenvironment of the Longjie silt bed," Quaternary Science, vol. 10, pp. 354-362, 1990.

[21] F. Jiang, X. Wu, and F. Qiang, "Silt bed of Longjie Area, Yuanmou Basin, Yuannan Province, China," in Loess, Quaternary Geology, Global Changes, pp. 99-106, Science Press of China, Beijing, China, 1996.

[22] Y.-Y. Chen, C.-Z. Li, S.-B. Wang, J.-L. Fu, Z.-S. Zhang, and F.C. Jiang, "Grain-size characteristics and origin of Longjie silt layer in the Yuanmou area, Yunnan, China," Geological Bulletin of China, vol. 28, no. 5, pp. 578-584, 2009.

[23] G. W. Berger, P. J. Mulhern, and D. J. Huntley, "Isolation of siltsized quartz grains from sediments," Ancient TL, vol. 11, pp. 8-9, 1980.

[24] H. M. Roberts, D. R. Muhs, A. G. Wintle, G. A. T. Duller, and E. A. Bettis III, "Unprecedented last-glacial mass accumulation rates determined by luminescence dating of loess from western Nebraska," Quaternary Research, vol. 59, no. 3, pp. 411-419, 2003.

[25] Z. Lai and H. Brückner, "Effects of feldspar contamination on equivalent dose and the shape of growth curve for osl of siltsized quartz extracted from Chinese loess," Geochronometria, vol. 30, no. 1, pp. 49-53, 2008.

[26] Y. C. Lu, X. L. Wang, and A. G. Wintle, "A new OSL chronology for dust accumulation in the last $130,000 \mathrm{yr}$ for the Chinese Loess Plateau," Quaternary Research, vol. 67, no. 1, pp. 152-160, 2007.

[27] J. R. Prescott and J. T. Hutton, "Cosmic ray contributions to dose rates for luminescence and ESR dating: large depths and longterm time variations," Radiation Measurements, vol. 23, no. 2-3, pp. 497-500, 1994.

[28] M. J. Aitken, An Introduction to Optical Dating, Oxford University Press, Oxford, UK, 2nd edition, 1998.

[29] D. A. Darby, J. Ortiz, L. Polyak, S. Lund, M. Jakobsson, and R. A. Woodgate, "The role of currents and sea ice in both slowly deposited central Arctic and rapidly deposited ChukchiAlaskan margin sediments," Global and Planetary Change, vol. 68, no. 1-2, pp. 58-72, 2009.

[30] L. Yi, H.-J. Yu, J. D. Ortiz et al., "Late Quaternary linkage of sedimentary records to three astronomical rhythms and the Asian monsoon, inferred from a coastal borehole in the south Bohai Sea, China," Palaeogeography, Palaeoclimatology, Palaeoecology, vol. 329-330, pp. 101-117, 2012.

[31] Q. Wang, X. Yang, N. J. Anderson, E. Zhang, and Y. Li, "Diatom response to climate forcing of a deep, alpine lake (Lugu $\mathrm{Hu}$, Yunnan, SW China) during the Last Glacial Maximum and its implications for understanding regional monsoon variability," Quaternary Science Reviews, vol. 86, pp. 1-12, 2014.

[32] L. Yi, X. Ye, J. Chen et al., "Magnetostratigraphy and luminescence dating on a sedimentary sequence from northern East China Sea: constraints on evolutionary history of eastern marginal seas of China since the Early Pleistocene," Quaternary International, vol. 349, pp. 316-326, 2014.

[33] J. D. Ortiz, "Application of visible/near infrared derivative spectroscopy to arctic paleoceanography," IOP Conference Series: Earth and Environmental Science, vol. 14, no. 1, Article ID 012011, 2011. 
[34] N. Jiang, R. Sun, and Q. Liang, "Late-Cenozoic deposits and mammalian faunas of Yuanmou Basin, Yunnan," Yunnan Geology, supplement 1, pp. 63-71, 1989.

[35] D. Sun, J. Bloemendal, D. K. Rea et al., "Grain-size distribution function of polymodal sediments in hydraulic and aeolian environments, and numerical partitioning of the sedimentary components," Sedimentary Geology, vol. 152, no. 3-4, pp. 263$277,2002$.

[36] H. Cheng, R. L. Edwards, W. S. Broecker et al., "Ice age terminations," Science, vol. 326, no. 5950, pp. 248-252, 2009.

[37] Y. Wang, H. Cheng, R. L. Edwards et al., "The holocene Asian monsoon: links to solar changes and North Atlantic climate," Science, vol. 308, no. 5723, pp. 854-857, 2005.

[38] Y. Wang, H. Cheng, R. L. Edwards et al., "Millennial- and orbital-scale changes in the East Asian monsoon over the past 224,000 years," Nature, vol. 451, no. 7182, pp. 1090-1093, 2008.

[39] Y. J. Wang, H. Cheng, R. L. Edwards et al., "A high-resolution absolute-dated late pleistocene monsoon record from Hulu Cave, China," Science, vol. 294, no. 5550, pp. 2345-2348, 2001.

[40] P. M. Grootes, M. Stulver, J. W. C. White, S. Johnsen, and J. Jouzel, "Comparison of oxygen isotope records from the GISP2 and GRIP Greenland ice cores," Nature, vol. 366, no. 6455, pp. 552-554, 1993.

[41] A. N. LeGrande and G. A. Schmidt, "Sources of Holocene variability of oxygen isotopes in paleoclimate archives," Climate of the Past, vol. 5, no. 3, pp. 441-455, 2009.

[42] S. C. Clemens, W. L. Prell, and Y. Sun, "Orbital-scale timing and mechanisms driving late pleistocene Indo-Asian summer monsoons: reinterpreting cave speleothem $\delta^{18} \mathrm{O}$," Paleoceanography, vol. 25, no. 4, Article ID PA4207, 2010.

[43] F. S. R. Pausata, D. S. Battisti, K. H. Nisancioglu, and C. M. Bitz, "Chinese stalagmite $\delta^{18} \mathrm{O}$ controlled by changes in the indian monsoon during a simulated heinrich event," Nature Geoscience, vol. 4, no. 7, pp. 474-480, 2011.

[44] B. A. Maher and R. Thompson, "Oxygen isotopes from chinese caves: records not of monsoon rainfall but of circulation regime," Journal of Quaternary Science, vol. 27, no. 6, pp. 615624, 2012.

[45] M. Tan, "Circulation effect: response of precipitation $\delta^{18} \mathrm{O}$ to the ENSO cycle in monsoon regions of China," Climate Dynamics, vol. 42, no. 3-4, pp. 1067-1077, 2014. 

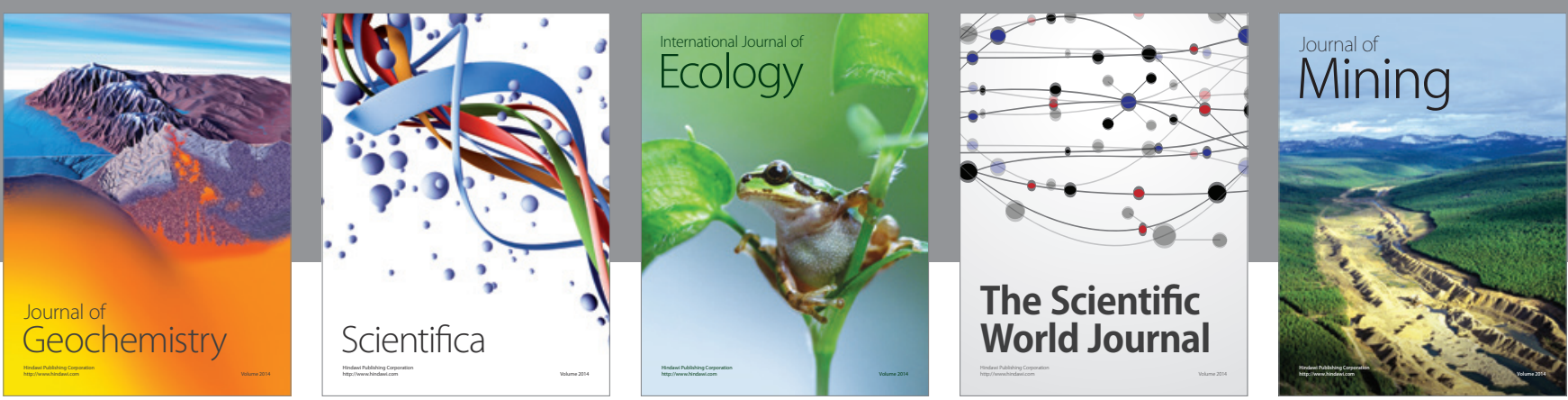

The Scientific World Journal
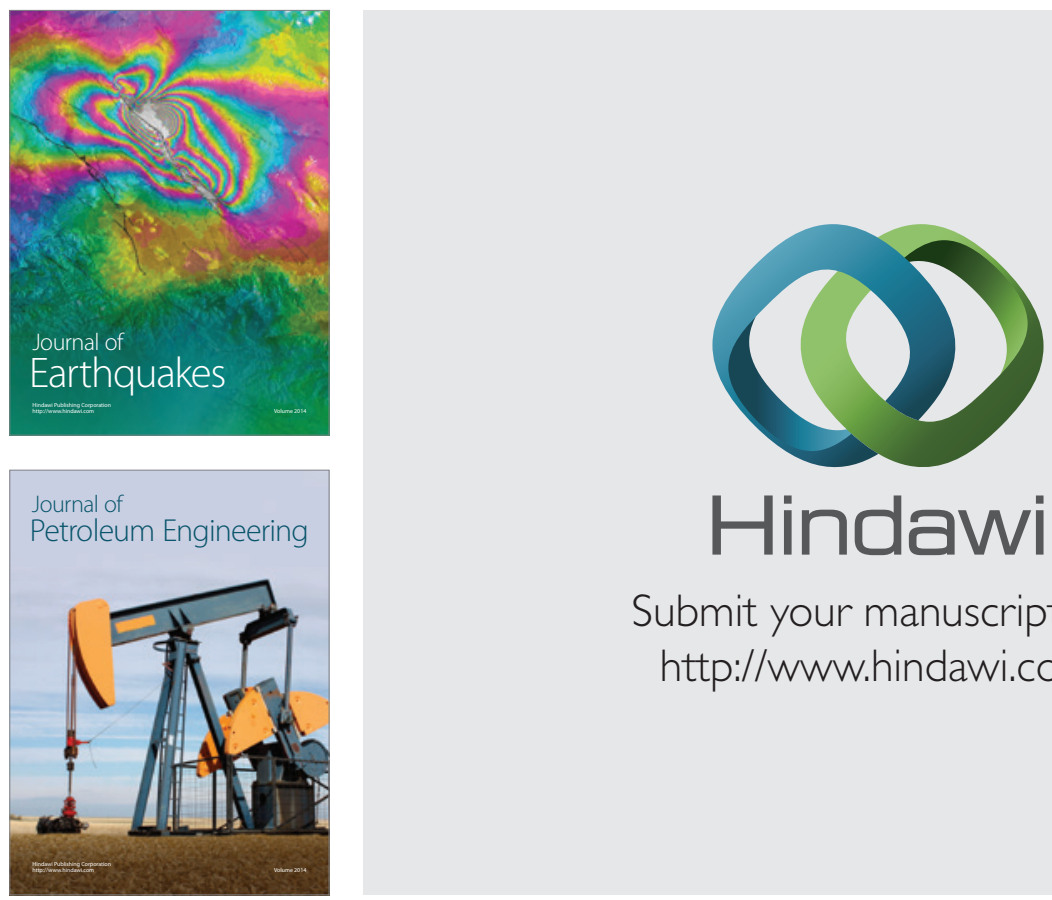

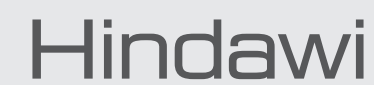

Submit your manuscripts at

http://www.hindawi.com
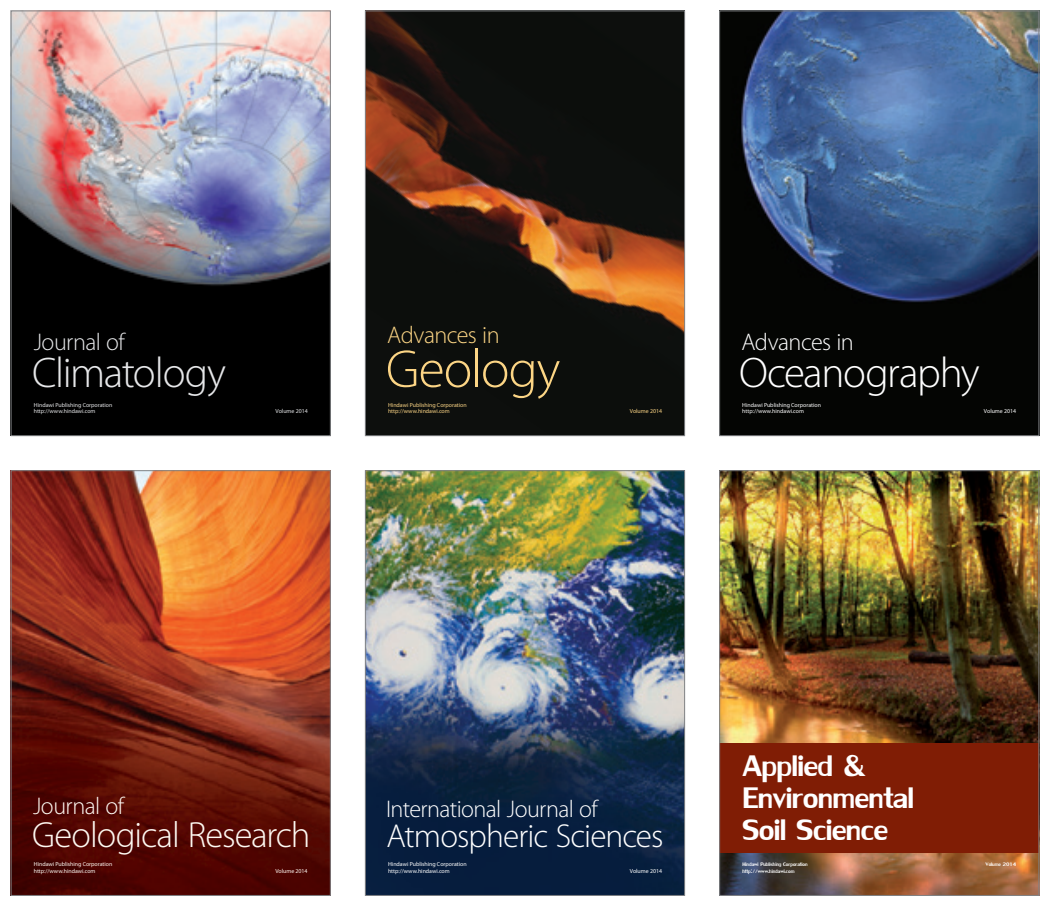
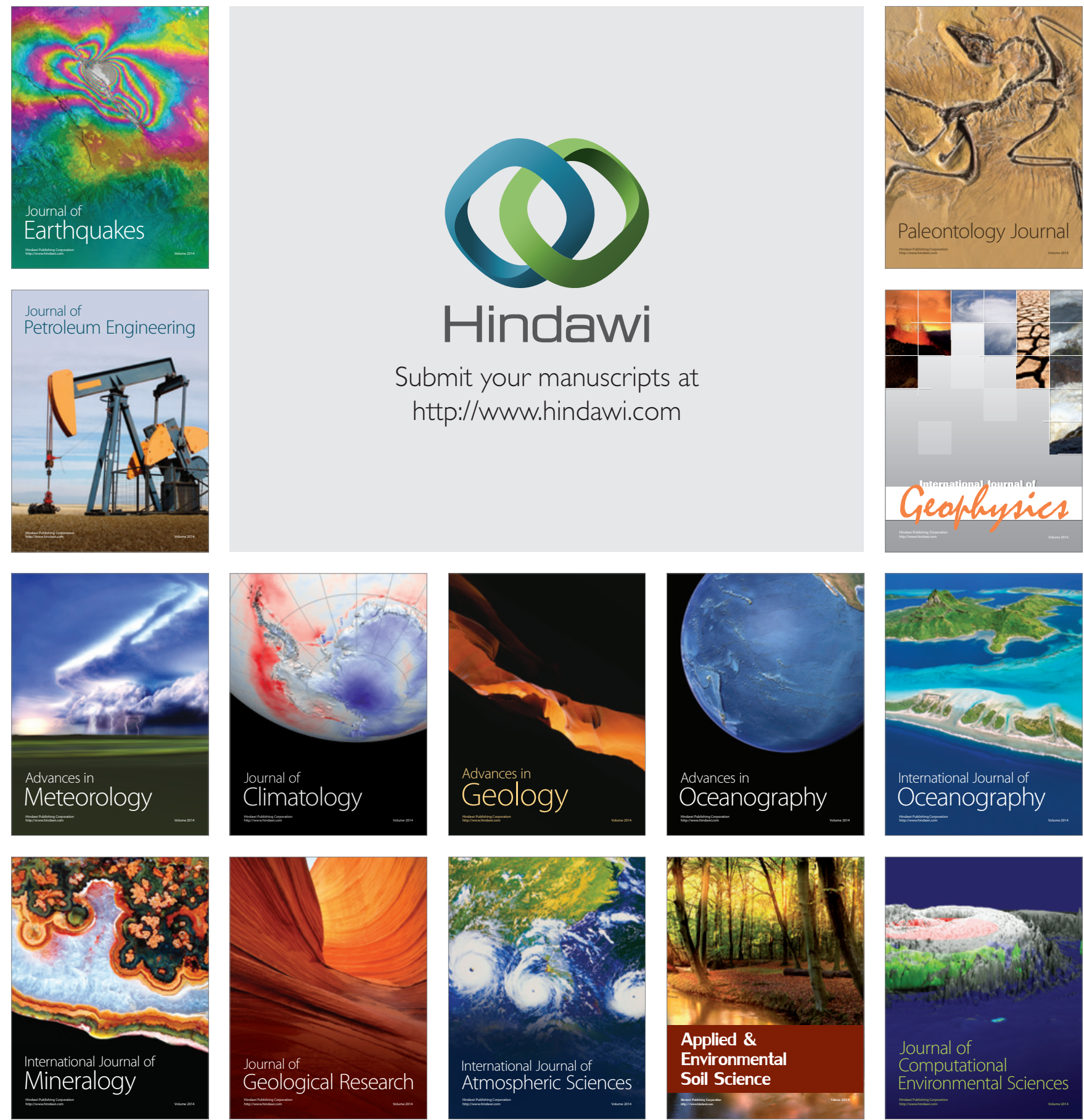